\title{
ДИСКУССИИ
}

DOI: https://doi.org/10.15688/jvolsu2.2017.1.15

UDC $81: 801.73$

Submitted: 03.10.2016

LBC 81.055 .52

Accepted: 08.11.2016

\section{THE LINGUISTIC PERSONALITY FROM THE VIEWPOINT OF HERMENEUTICS AND PHENOMENOLOGY: PROBLEM STATEMENT}

\author{
Aleksandr V. Zagumennov \\ Vologda State University, Vologda, Russian Federation
}

\begin{abstract}
The article, which consists of 5 parts, is devoted to the problem of connection between linguistic personology, on the one hand, and hermeneutics and phenomenology, on the other hand. This viewpoint is contrary to the generally accepted view of most scientists, which displays the relationship of this discipline with the philosophy of personalism. The article's introduction provides a brief description of the problem field of linguistic personality theory. This discipline was finally formed in Russia in the 1980s. The next two sections are devoted to the analysis of theoretical studies. The theoretical material substantiates the potential existence of an invariant organization of understanding, which largely coincides with the three-level model of linguistic personality in the conception by Yu.N. Karaulov. The connection of hermeneutics and phenomenology paradigms in the studied linguistic discipline is determined by many reasons, including historical and methodological ones. The results of a number of comparisons refute the possibility of referring to the linguistic personality theory as a "linguistic personology" because its terminology and investigative procedures are represented in more ancient philosophical systems closely related to philological sciences. Due to the fact that the text is understood as a folded author's activity fundamentally amenable to its unfolding, the researcher should focus on functional transitions, shifts, displayed by language resources.

As an empirical application of the approach the author describes interpretation of quotations from the Holy Book in the I.A. Khvorostinin's short novel Slovesa dney i tsarey $i$ svyatiteley Moskovskikh ezge est $v$ Rossii ('Words of Days, Tsars and Saint Bishops of Moscow, Russia') as a series of specific steps aimed at disclosing semantic connection with extralinguistic reality. Besides, the author differentiates the author's individual interpretation of the sign and the author's individual interpretation of historical events. The author notes a potential alternativeness of hermeneutics and phenomenology to developments in the field of cognitive linguistics, and their application in the study of the texts of the first half of the 17th century allows to show the verbal behavior of native speakers in the conditions of social and cultural crisis of the Time of Troubles.
\end{abstract}

Key words: linguistic personology, hermeneutics, phenomenology, linguistic personality, text, interpretation.

УДК $81: 801.73$

ББК 81.055 .52

Дата поступления статьи: 03.10.2016

Дата принятия статьи: 08.11.2016

\section{ГЕРМЕНЕВТИКО-ФЕНОМЕНОЛОГИЧЕСКИЙ АСПЕКТ ИЗУЧЕНИЯ ЯЗЫКОВОЙ ЛИЧНОСТИ: К ПОСТАНОВКЕ ПРОБЛЕМЫ}

\author{
Александр Владимирович Загуменнов \\ Вологодский государственный университет, г. Вологда, Российская Федерация
}

Аннотация. Статья посвящена проблеме связи лингвистической персонологии с герменевтикой и феноменологией. На теоретическом материале обосновывается потенциальное существование инвариантной 
организации понимания, которая во многом совпадает с трехуровневой моделью языковой личности в концепции Ю.Н. Караулова. Соединение парадигм герменевтики и феноменологии в теории языковой личности обусловлено многими причинами, в том числе историческими и методологическими. Приведенные результаты ряда сопоставлений опровергают возможность рассмотрения «теории языковой личности» только как «лингвоперсонологии», поскольку ее терминология и процедуры исследования представлены в более древних философских системах, тесно связанных с филологическими науками. Поскольку текст понимается как свернутая деятельность автора, принципиально поддающаяся своему развертыванию, в процессе анализа выдвигается требование фокусировать исследовательское внимание на функциональных переходах, сдвигах, отображенных ресурсами языка. В качестве эмпирического применения подхода описана интерпретация цитат из Священного Писания в повести И.А. Хворостинина «Словеса дней и царей и святителей Московских еже есть в России» как последовательность определенных шагов раскрытия смысловой связи с внеязыковой действительностью. В статье разграничиваются индивидуально-авторское толкование знака и индивидуально-авторское толкование исторического события. Отмечена потенциальная альтернативность герменевтики и феноменологии разработкам в области когнитивной лингвистики, а их применение при исследовании текстов первой половины XVII в. позволяет показать речевое поведение носителей языка в условиях социокультурного кризиса Смутного времени.

Ключевые слова: лингвоперсонология, герменевтика, феноменология, языковая личность, текст, интерпретация.

\section{1. Введение}

Наиболее разработанными на данном этапе становления лингвоперсонологии как научной дисциплины являются вопросы истории развития ее терминологического аппарата, некоторые аспекты изучения языковой личности, ее общей структуры (подробнее в: [Богин, 1984, 2009; Виноградов, 1980; Гайнуллина, 1996; Иванцова, 2010 и др.]). В меньшей степени освещались вопросы методологического расширения и инерции структурно-системного подхода как фактора, редуцирующего антропоцентрическую направленность поисков особенностей идиостиля (см. в: [Богин, 1984; 2009; Иванцова, 2010; Караулов, 2010; Тхорик, 2000; Языковая личность..., 2014, 2016 и др.]).

Важнейшей категорией в лингвоперсонологии является языковая личность, понимаемая, вслед за Ю.Н. Карауловым, как «личность, реконструированная в основных своих чертах на базе языковых средств» [Караулов, 2010, с. 35]. Необходимо отметить, что данное определение выступает и как герменевтический принцип изучения авторского (индивидуального или коллективного) письма. Исследователь, опираясь на факты в тексте, реконструирует значимые опорные точки в модели, которая замещает реального автора (или условно соответствует ему). Единство каждого последующего этапа анализа поддерживается тем, что реконструкция определенного фрагмента модели (языка, картины мира, поведения) при диахроническом подходе требует «возвращения» исследователя к памятнику, но с иных методологических позиций и с иной степенью понимания. Таким образом, на первый план выдвигается интерпретация как фундаментальная процедура научного рассмотрения объекта лингвоперсонологии.

Одним из первых связь теории языковой личности и герменевтики отметил Г.И. Богин [Богин, 1984]; позже на необходимость этого пересечения указывала Н.И. Гайнуллина [Гайнуллина, 1996], а в докторской диссертации В.И. Тхорика этот вопрос уже обсуждается в рамках отдельного раздела [Тхорик, 2000].

Как своего рода манифест можно рассматривать книгу «Языковая личность. Моделирование, типология, портретирование. Сибирская лингвоперсонология», где переход от когнитивной лингвистики к герменевтике становится программным при исследовании и описании типов интерпретаторов - лиц, осуществляющих толкование текста в условиях поставленного авторами издания эксперимента. Все это позволяет говорить об актуализации герменевтико-феноменологического аспекта лингвоперсонологии.

\section{2. Связь инварианта структуры понимания и грамматики языка}

Проблема интерпретации была поставлена в античности, но ее переосмысление осуществлялось на исходе Средних веков. Гер- 
меневтика этого времени начала поиск адекватного представления о структуре понимания как исходной точке любого истолкования.

Вероятно, первые результаты такого рода исследований зафиксированы уже в XVI в. в работах по экзегетике лютеранского богослова М. Флация. Так, применительно к Священному Писанию им выделяются «четыре понимания», где каждое последующее маркируется увеличением составляющих единиц по ходу развертывания воспринимаемого текста: «1) первое понимание - то, посредством которого читатель понимает отдельные слова и звуки $<\ldots>$ оно требует знания соответствующего языка; 2) [второе - то], посредством которого понимают смысл речи, которую составляют слова в отдельных периодах $<\ldots>$; 3) [третье] <..> - "посредством которого слушатели понимают дух говорящего, будь то Бог, пророк, апостол или евангелист. Духом я называю разум, мысль, замысел и намерение говорящего. Так можно понять не только что говорится, но и почему и зачем" <..> 4) [четвертое] - посредством которого понимается частное употребление каждого места Священного Писания...» (цит. по: [Шпет, 2004, с. 269]). Из приведенного фрагмента можно вывести ряд тезисов: «понимание говорящего принципиально возможно», «грамматика языка - основа интерпретации» и т. д. И хотя истолкование здесь - деятельность воспринимающей текст личности, были даны предпосылки для последующего перехода от восприятия к научному моделированию некоего подобия порождающих структур у отправителя текста. Так выстраивается цепь вида «реципиент $\leftrightarrow$ знак $\leftrightarrow$ продуцент» с доминантой третьего компонента.

В концепции, выдвинутой Ф. Астом, фокус исследовательского внимания смещается с вида понимания на его аспект. Согласно предположению Ф. Аста, понимание является трояким: «1) историческим по отношению к содержанию произведения, 2) грамматическим по отношению к форме или языку и 3) духовным по отношению к духу отдельного писателя и всей древности» (цит. по: [Шпет, 2004, c. 312]). Данное представление о понимании предполагает выдвижение тезиса о намеренной организации текстовой деятельности адресанта в тесной связи с опытом ее восприя- тия адресатом. Другими словами, это тот же вид цепи «реципиент $\leftrightarrow$ знак $\leftrightarrow$ продуцент», но с доминантой первого компонента.

Параллельно с Ф. Астом исследования вел Ф. Бёк. Им вводятся «объективные условия» процесса понимания, среди которых не последнюю роль играют связи внутри языковой системы. В своей концепции Ф. Бёк выделил «грамматическую интерпретацию». Согласно его предположению, она «должна понять каждый элемент языка - само слово, его грамматические и синтаксические формы: 1) в его основном значении, 2) в специальных условиях времени и сферы его применения, и, наконец, смысл данного слова в его связи, в его “языковой обстановке”, как со стороны материальной, так и формальной...» (цит. по: [Шпет, 2004, с. 351]). Мы можем только предположить, что в области грамматической интерпретации фокус в цепи «реципиент $\leftrightarrow$ знак $\leftrightarrow$ продуцент» смещен на центральный компонент, то есть текст.

Цитируемая работа Г.Г. Шпета готовилась к изданию в 1920-е гг., но была впервые опубликована только в 1990 году. Это является еще одним доказательством того, что некоторые герменевтические разработки, которые предвосхитили модели языковой личности, долгие годы оставались не только невостребованными, но и вовсе забытыми. В середине XX в. легитимное построение герменевтики на базе философии идеалистического толка было невозможным. Первые опыты решения проблемы понимания на фундаменте материализма проводил московский методологический кружок под руководством Г.П. Щедровицкого, в который входил и Г.И. Богин. На протяжении десятилетий этим коллективом вырабатывался инструментарий исследования мышления и коммуникации.

Частично повторив логику размышлений Г.Г. Шпета, Г.И. Богин с 1970-х гг. выдвигает концепцию филологической герменевтики, основу которой составили лингводидактика и отечественные аналоги зарубежных психологических разработок в сфере исследования готовностей. Новая концепция Г.И. Богина поднимала проблему моделирования динамики усвоения языковой системы у субъектов образовательного процесса на научном фундаменте материалистически ориентированной советской 
A.B. Загуменнов. Герменевтико-феноменологический аспект изучения языковой личности

высшей школы. Это не только привело к актуализации термина В.В. Виноградова «языковая личность», но и стало своеобразной точкой отсчета для всей лингвоперсонологии. Появляется первая модель со своими структурными уровнями - правильности, интериоризации, насыщенности, адекватности выбора и адекватного синтеза (подробнее в: [Богин, 1984, с. $7-$ 9]), единицами и практическим применением. В этой концепции находит решение и проблема типов понимания, которых, по мнению Г.И. Богина, в чистом виде три: семантизирующее, когнитивное и распредмечивающее (см. подробнее в: [Богин, 2009]).

Иным путем шел Ю.Н. Караулов в книге «Русский язык и языковая личность». Используя теоретико-научный потенциал языкознания, социологии, психологии, информатики и т. д., он разработал трехуровневую функциональную модель, включающую вербально-семантический, лингво-когнитивный (тезаурусный) и мотивационный уровни. Как представляется, Ю.Н. Караулов в своей концепции (и на иных основаниях) пришел к структуре, сходной с герменевтическими разработками. Теоретически выведенные им уровни языковой личности в рамках представленного нами гуманитарного контекста коррелируют, например, с аспектами понимания в разработках Ф. Аста: историческое содержание - картина мира, тезараус; грамматика - вербально-семантическая сеть; духовное (= мыслительное) отображение автора - прагматикон как область мотивов, коммуникативных потребностей. Вместе с тем следует признать, что указанные междисциплинарные сходства напрямую друг с другом не связаны. В парадигме языкознания представления об организации понимания, которые были выделены в герменевтике как имманентно данные лицу-интерпретатору в точке реципиента, перенесены в филологии посредством специфически исследовательской установки сознания в положение объекта-автора, заняв позицию продуцента, обладающего теми же составляющими и организацией. Тогда по логике этого движения «лингвистическая персонология» уходит корнями не в философию персонализма, а в экзегетику и герменевтику. В дальнейшем мы отметим еще один вектор, способствовавший выдвижению одного из ключевых понятий XX в. - языковой личности.

\section{3. Феноменологический момент в контексте оформления понятия «языковая личность»}

В трудах В.В. Виноградова понятие «языковая личность» появляется в 1930-е годы. При этом подавляющим большинством исследователей не принимается во внимание контекст выдвижения этого понятия. Согласно сведениям комментаторов трудов В.В. Виноградова, в 1926-1927 гг. «...в круг его чтения и “слушания" входят такие авторы (некоторые из них не отражены в библиографическом аппарате его работ), как С. Аскольдов, А. Белый, Э. Гуссерль, А.С. Долинин, Х. Зигварт, Вяч. Иванов, Б.В. Казанский, А.Ф. Лосев, Л.В. Пумпянский, Вл. Соловьев, Е.Н. Трубецкой, Н.С. Трубецкой (здесь мы имеем в виду нелингвистические работы), С.Л. Франк, Г.Г. Шпет, Б.М. Энгельгардт» (цит. по: [Виноградов, 1980, с. 313]). В данный список действительно входят философы-персоналисты, но их роль в выдвижении понятия «языковая личность» незначительна. Э. Гуссерль - основатель нового типа феноменологии - философского направления, «задачи к-рого: 1) освободить филос. мышление от натуралистич.объективистских установок, 2) конституировать спец. область спекулятивного знания рефлексию сознания о своих актах и о данном в них содержании, 3 ) выявить с помощью определ. методологии, средств (редукции, рефлексии) изнач. основы культуры» [Философская энциклопедия, 1970, с. 314]. А.Ф. Лосев использовал в своих трудах разработки данной парадигмы. Г.Г. Шпет проходил стажировку у Э. Гуссерля и являлся одним из популяризаторов его концепции. Б.М. Энгельгардт, по замечанию А.Б. Муратова, «как бы “догуссерлианский” вариант феноменологии» (цит. по: [Энгельгардт, 2005, с. 405]).

В.В. Виноградов выразил свои теоретико-методологические основания, цитируя L. Spitzer’a: ““Языковое” - прежде всего объект феноменологического исследования сущности... Писатель, исходя из языка, конструирует новую логику вещей: получается не конструкция слов, но адаптация смысла к являющимся словам» (цит. по: [Виноградов, 1976, с. 23]). С одной стороны, так продолжалась «логическая» линия в интерпретации син- 
таксиса и грамматики, появлялись перспективы выйти на решение вопроса о тех структурах, которые «устраивают» язык, с другой развивалось академическое гумбольдтианство, идущее от работ А.А. Потебни. «Метод» харьковской школы не включал формальную организацию произведения, у функционировавшего тогда ОПОЯЗа в большей степени игнорировалась образная составляющая текста. Радикальный шаг В.В. Виноградова заключался в синтезе сильных сторон этих концепций с опорой на феноменологическую философию. Языковое сознание стало еще одним объектом исследования в филологии. Для его изучения В.В. Виноградов выделил два метода, по крайней мере в области исторической стилистики.

\section{Функционально-имманентный метод}

В работах о стиле Н.В. Гоголя этот метод называется феноменологическим (но не «персонологическим»!): «И этот метод “феноменологического” описания следует отличать от того лично заинтересованного, пронизанного вкусами и влечениями одной эпохи “импрессионистского” созерцания и изучения, которому подвергается творчество и стиль поэта в моменты высшего подъема, “воскресения” интереса к нему» [Виноградов, 1976, c. 232]; «Имманентный, “феноменологический” анализ в основных своих частях проглянет лишь в конце статьи; однако на всем протяжении ее он будет руководить и системой литературных сопоставлений, и их общим направлением» [Виноградов, 1976, с. 142]. Обратим внимание на выделение термина с помощью кавычек. Вероятно, это можно рассматривать как опыт подбора нужной номинации, выбор похожего по направлению, но в строгом смысле слова не соответствующего своему изначальному применению в связи с модификацией контекста и практического использования.

\section{Ретроспективно-проекционный метод}

Термин «ретроспективно-проекционный метод» синонимичен термину «исторический метод». «Для него основная проблема - сопоставление стилистических явлений, проектиру- емых вовне и рассматриваемых в хронологической последовательности с точки зрения их сходства, в целях установления формул, выражающих порядок их чередования и смены» [Виноградов, 1980, с. 39-41]. Синтез сильных сторон концепций харьковской школы и ОПОЯЗа сопровождался дифференциацией: с одной стороны - «языковая личность» с ее содержанием, с другой - текст, построенный по приемам жанровой организации.

Во второй половине XX в., помимо становления психо- и социолингвистики, происходит пересмотр лингводидактических концепций. Появляется необходимость исследования речевой деятельности в онтогенезе в соответствии с теми лингвистическими представлениями о грамматике, которые к этому периоду уже были сформированы. Требуется создание фикции всего «Homo loquens», чтобы на основе ее параметров говорить о степени готовности воспринимать / создавать тексты. Именно такой вектор движения прослеживается в трудах Г.И. Богина. При разработке способов изучения языковой личности очевиден авторский интерес к гуссерлианству, но одновременно - спор и расхождение с ним. Отображено это в специальном замечании о «феноменологической процедуре» исследования. В концепции Г.И. Богина она состоит из четырех операций. «Идейная, содержательная сущность сообщения программируется автором как один из моментов отражения действительности.

Автор создает текст, и текст выступает как вторичная материальная система, опредмечивающая в своих формах эту программу. Это опредмечивание - часть художественной деятельности.

Реципиент воспринимает текст как материальную систему и распредмечивает его идеальное, идейное содержание. Такое распредмечивание - часть художественного освоения действительности.

Реципиент в той или иной мере присваивает его содержание и включает его в программы своей деятельности, то есть человек изменяется в ходе этого, как и всякого другого, рода познавательной деятельности» [Богин, 2009, с. 103].

Вероятно, интерес Г.И. Богина к области герменевтики как частного случая фено- 
менологии повлиял на становление теории языковой личности, а сама концепция со временем стала альтернативным подходом к исследованию взаимосвязи языка и мышления, речи и сознания, знака и личности.

\section{4. Реконструкция интерпретации как деятельности языковой личности первой половины XVII века}

Гипотезы о том, что текст должен рассматриваться как деятельность его создателя, как продукт сознательно-мыслительного процесса, как ключ и доступ к внутреннему миру автора высказывались неоднократно [Гальперин, 2006; Штайн, 2006; Яцкевич, 1999 и др.]. Тем не менее данная точка зрения пока не находит поддержки в исследованиях, посвященных истории языка. В этой области основополагающие труды были достижением структурно-системной парадигмы до того, как текст оказался полноправным объектом лингвистического изучения. Для анализа деятельности личности при диахроническом подходе внимание должно быть сфокусировано не только на отдельных грамматических категориях, но и на памятнике в целом ${ }^{1}$.

Материалом для анализа в данной работе послужила повесть И.А. Хворостинина «Словеса дней и царей и святителей Московских еже есть в России», датируемая первой половиной XVII в., на которую приходится расцвет светской публицистики. Интерес к этому памятнику письменности обусловлен не только его недостаточной изученностью, но в первую очередь тем, что его автор был участником многих событий Смутного времени.

\section{Герменевтика знака и события}

В повести И.А. Хворостинина приводятся четырнадцать дословных цитат из Священного Писания, одна из которых подвергается авторскому осмыслению: Во-истинну аки о немъ (о Лжедмитрии - A. 3.) велегласный Пророкь Іезекіиль глаголеть сиие: «И ты, сквернавый стар тйшина Израилевъ, его же день пріиде во время неправды. Се глаголеть Господь: сложи клобукь и положи в ънець; смири высокая и вознесе смиренная. Неправдою неправду положу я и та не такова будетъ» (стб. 540) ${ }^{2}$. С точки зрения И.А. Хворостинина, самозванец преступил добродетель смирения - едва ли не определяющую категорию христианского православного мировоззрения, что привело к гордыне, являющейся грехом. Отсюда лексикосинтаксическое оформление культурного смысла, которое напрямую связано с деятельностью автора как языковой личности: Зрите силу слова Пророческаго: нарицают его сквернавымъ начальникомъ Израилевым (стб. 540). То, что было высказано по отношению к «сквернавому начальнику», переносится на личность Лжедмитрия, и автор акцентирует читательское внимание именно на атрибутивном словосочетании (нарицают его сквернавымъ начальникомъ). Внимание к языковым единицам позволяет говорить об элементаристкой стратегии интерпретации, когда общий смысл фразы определяется исходя из значения составляющих ее элементов (см. об этом: [Языковая личность..., 2014, c. 90]). Повествование сменяется каскадом вопросов: Гд $\mathbf{t}$ убо Израилю началникъ? гд $\mathbf{t}$ есть началникь Жидовскій? гд ст стар қйшинствуеть Израиль? (стб. 540). Задается «рефлекторная дуга» (Ю.Н. Караулов), программирующая варианты и содержание ответов. Интерес представляет тот факт, что И.А. Хворостинин эксплицирует значимость в осмысляемом фрагменте из Священного Писания грамматической категории числа: Под областію бо многихъ старьйшинъ христіанскихъ и бусурманскихъ пребываетъ и досел中 Жидовской родъ; аще бы о $m$ tхx глаголаль, но множественно бы число предложсиль Пророкъ, рекъ бы: Старқйшины Израилевы; но не тако, не единого стар ъйшину укоряеть божественный Пророкъ (стб. 540). В рассматриваемом фрагменте текста сквернавыцй (стар қйшина) как качественное прилагательное противопоставлено относительным (христіанскихъ, бусурманскихъ, божественный). Тяготение к последним прослеживается в самоидентификации представителя этноса, говорящего от лица коллектива: $\mathrm{Mbl}$ убо во-истинну истинн $\mathbf{6}$ нарицаемся Израильтяне новопросв 中щенныя... (стб. 540). Если учитывать, что употребление грамматических форм настоящего или прошедшего времени определено специ- 
фикой восприятия интерпретатора, то последний пример позволяет говорить о завершении рефлекторной дуги. В точке «сейчас» был дан осмысляемый фрагмент Священного Писания (Во-истинну аки о немъ велегласный Пророкъ Іезекіиль глаголеть сице). В начале своей интерпретации этой цитаты И.А. Хворостинин также пишет: Зрите силу слова Пророческаго: нарицают его, далее - пребываemъ и досел 't. По отношению к последнему выражению и происходит смена изъявительного наклонения на условное, что детерминирует изменение морфем, соотносимых с прошедшими событиями: аще бы $о \mathrm{~m} \mathbf{k} x \mathrm{~b}$ глаголаль, но множественно бы число предложиль Пророкъ, рекъ бы... Обратный переход осуществляется в той же синтаксической конструкции, но в другой ее части (но не тако, не единого стар вйшину укоряетъ божественный Пророкъ), то есть перед нами динамика «настоящее - прошедшее - настоящее».

Завершив интерпретацию знаковых последовательностей, И.А. Хворостинин задает еще одну рефлекторную дугу, направленную на осмысление исторического события: $\mathrm{Ce}$ слово Пророческое указуеть сквернав ъйшего стар фйшину Израилева, неправдою неправедно полагая и вознося смиренная и смиряя высокая. Не сей ли есть? Не смири ли въ высокихъ иаря Бориса, не вознесе ли смиренныя, не сня ли клобукъ и не положиль ли на ся проклятія в внецъ, и та вся н $\mathbf{k c m ь ~ т а к о в а я , ~ я к о ~ ж е ~ в о с х о т ~} \mathbf{k}$ ? (стб. 541). В текстовой категории ретроспективности реализуется свернутое содержание приведенного фрагмента, и одно предложение оказывается соотносимым со сложным синтаксическим целым. Культурный и исторический фон переплетаются интерпретативной деятельностью автора, опредмечиваясь с помощью ресурсов языка.

\section{Компрессия прецедентного текста}

Первые работы в теории языковой личности, посвященные данному процессу, вероятно, были написаны Г.И. Богиным, где эта проблема была им поставлена как лингводидактическая [Богин, 2009]. Тем не менее нам точно неизвестно, были ли эти разработки эк- страполированы в область диахронической лингвоперсонологии.

Сочинение И.А. Хворостинина позволяет предпринять исследование компрессии прецедентного текста путем сравнения Священного Писания и тех его фрагментов, которые были включены с некоторыми изменениями в рассматриваемую повесть.

Интерес вызывает эпизод, описываемый в 5 главе книги Пророка Даниила в «Острожской Библии» издания 1581 г..... и похвали́ш ${ }^{a}$ боги́ златыл и сре́бреныл, и м

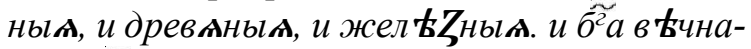
го небслвиша. Мы используем данный источник как наиболее близкий по хронологии к годам жизни И.А. Хворостинина. Обращаться к изданиям более позднего времени некорректно: во второй половине XVII в. начнется правка церковных книг, а в рамках исследования необходимо использовать исходный контекст.

В тексте И.А. Хворостинина приведенный выше фрагмент дан в неточном пересказе: $\mathrm{He}$ сльшиал ли еси николиже, о иарю, како Валтасарь иарь Перскій, сынъ Навходоносора иаря, изнесе сосуды изъ храма Божія, иже бъ во Іерусалим $\mathbf{k}$, и похвали боги златьля $u$ сребряныя и медяныя, Бога же святаго и истиннаго Вседержителя не похвали (стб. 538). Сравним два словесных ряда, представленных в источнике и сочинении:

1) и похвали́ш боги́ златыл $и$ сре́бре-

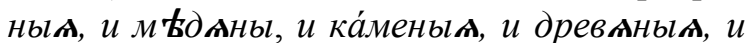
жел $\mathbf{z}$ ныл (Острожская Библия);

2) и похвали боги златыя и сребряныя и медяныя («Словеса дней...»).

Выбор первых трех прилагательных (златыля и сребряныя и медяныя) для автора произведения является достаточным: не имеет значения материал, из которого изготовлены идолы, их количество и последовательность, но важно то, что они - часть темного язычества, это и определяет объем переданного содержания. Компрессии подверглась только та часть, которая напрямую была связана с описанием истуканов. Отмечаемые выше изменения вызваны не только грамматическими особенностями передачи события в аспекте видо-временных отношений (и похвали́ш ${ }^{a}-u$ похвали), но и дополнением исходного фрагмента. Сравним еще два ряда, представленных в источнике и сочинении: 

Библия);

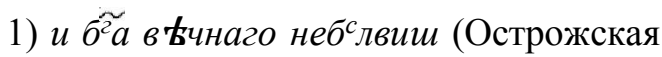

2) Бога же святаго и истиннаго Вседержителя не похвали («Словеса дней...»).

Лексико-синтаксическое распространение атрибутивного словосочетания ( $\sigma^{2} a$ в tчнаго) до образования двух связных между собой синтагм (Бога святаго и истиннаго Вседержителя) сопровождается специфической заменой прилагательных. Для автора факт «вечности» малозначителен, на первый план выносится то, что Бог - святой и истинный Вседержитель. Феноменологическое рассмотрение осложняет интерпретацию данной лексической замены. Перед нами, вероятно, глубинное различение «вечности» и «истинности» как непересекающихся структур в индивидуальной картине мира: истина оказывается вне времени, поэтому категория вечного есть ограничение по темпоральному признаку, что не может быть применено по отношению к Вседержителю. Первый элемент сложного слова уже отрицает возможность выстроить рамки божественного.

\section{5. Заключение}

Признание текста явлением динамическим, результатом деятельности, фрагментарно сохранившим в самой своей организации точки своего развертывания, позволяет перейти от пассивно-аналитического разложения грамматики пишущего к дескрипции авторских имманентных процессов, опредмеченных в знаковом пространстве. Вместе с тем такая постановка проблемы ведет к реставрации герменевтических и феноменологических разработок отечественной филологии XIX$\mathrm{XX}$ вв. как альтернативных когнитивистских парадигм. Применительно к истории языка, в частности семнадцатого столетия, это может изменить общее представление о причинах системных сдвигов (от фонетики до синтаксиса), корень которых видится нам в качественном преобразовании ресурсов коммуникации в условиях кризиса традиционного уклада русской жизни. Появление светской публицистики, к которой относятся повести И.А. Хворостинина, было коллективным опытом интерпретации причин возникновения Смутного времени, поэтому на первый план выходят истолкование знаков (лингвистических или исторических) и компрессия прецедентных текстов (для передачи сходства событий минувшего и настоящего).

\section{ПРИМЕЧАНИЯ}

1 Лингвоперсонологические разработки использовались, например, при исследовании «русского» Архива гетмана Яна Петра Сапеги 1608 1611 гг. (см. в: [Тупикова, 2007]).

2 Цит. по изд.: Русская историческая библиотека, издаваемая археографическою комиссиею. СПб. : Типографія И.Н. Скороходова (Надеждинская, 43), 1891. - Т. 13. - 982 стб. Орфография оригинала сохранена.

\section{СПИСОК ЛИТЕРАТУРЫ}

Богин, Г. И. Модель языковой личности в ее отношении к разновидностям текстов : автореф. дис. ... д-ра филол. наук / Богин Георгий Исаевич. Л., 1984. $-33 \mathrm{c}$.

Богин, Г. И. Обретение способности понимать: работы разных лет / Г. И. Богин. - Тверь : Твер. гос. ун-Т, 2009. - Т. 1. -256 с.

Виноградов, В. В. О языке художественной прозы / В. В. Виноградов. - М. : Наука, 1980. - 360 с.

Виноградов, В. В. Поэтика русской литературы / В. В. Виноградов. - М. : Наука, 1976. - 511 с.

Гайнуллина, Н. И. Эпистолярное наследие Петра Великого в истории русского литературного языка : автореф. дис. ... д-ра филол. наук / Гайнуллина Надежда Ивановна. - Алматы, 1996. - 54 с.

Гальперин, И. Р. Текст как объект лингвистического исследования / И. Р. Гальперин. - М. : КомКнига, 2006. - 144 с.

Иванцова, Е. В. Лингвоперсонология: Основы теории языковой личности / Е. В. Иванцова. Томск : Изд-во Том. ун-та, 2010. - 160 с.

Караулов, Ю. Н. Русский язык и языковая личность / Ю. Н. Караулов. - М. : Изд-во ЛКИ, 2010. -264 с.

Тупикова, Н. А. О выражении славянской языковой личности в деловых текстах начала XVII века / Н. А. Тупикова // Вестник Волгоградского государственного университета. Серия 2, Языкознание. - 2007. - № 6. - С. 168-173. - Электрон. текстовые дан. - Режим доступа: http://cyberleninka.ru/ article/n/o-vyrazhenii-slavyanskoy-yazykovoylichnosti-v-delovyh-tekstah-nachala-xvii-veka (дата обращения: 05.02.2017).

Тхорик, В. И. Языковая личность: лингвокультурологический аспект : автореф. дис. ... д-ра филол. наук / Тхорик Владимир Ильич. - Краснодар, 2000. $-304 \mathrm{c}$. 
Философская энциклопедия / гл. ред. Ф. В. Константинов. - М. : Советская энциклопедия, 1970. - T. 5. $-740 \mathrm{c}$.

Шпет, Г. Г. Мысль и Слово. Избранные труды / Г. Г. Шпет. - М. : РОССПЭН, 2004. - 688 с.

Штайн, К. Э. Гармония поэтического текста / К. Э. Штайн. - Ставрополь : Изд-во СГУ,2006. -646 с.

Энгельгардт, Б. М. Феноменология и теория словесности / Б. М. Энгельгардт. - М. : Новое литературное обозрение, 2005. - 464 с.

Языковая личность. Моделирование, типология, портретирование. Сибирская лингвоперсонология / под ред. Н. Д. Голева, Н. Н. Шпильной. - М. : Ленанд, 2014. - Вып. 1. - 637 с.

Языковая личность. Моделирование, типология, портретирование. Сибирская лингвоперсонология / под ред. Н. Д. Голева, Н. В. Мельник, С. В. Оленева. - М. : ЛЕНАНД, 2016. - ВЫп. 2. - 432 с.

Яцкевич, Л. Г. Структура поэтического текста / Л. Г. Яцкевич. - Вологда : Русь, 1999. - 240 с.

\section{REFERENCES}

Bogin G.I. Model yazykovoy lichnosti v ee otnoshenii k raznovidnostyam tekstov: avtoref. dis. ... $d$-ra filol. nauk [Model of Linguistic Personality in Its Relation to Varieties of Texts. Dr. philol. sci. abs. diss.]. Leningrad, 1984. 33 p.

Bogin G.I. Obretenie sposobnosti ponimat: raboty raznyh let [Gaining the Ability to Understand: Works of Different Years]. Tver, Tver. gos. un-t Publ., 2009, Vol. 1.256 p.

Vinogradov V.V. O yazyke khudozhestvennoy prozy [On the Language of Fiction]. Moscow, Nauka Publ., 1980. 360 p.

Vinogradov V.V. Poetika russkoy literatury [Poetics of Russian Literature]. Moscow, Nauka Publ., 1976. $511 \mathrm{p}$.

Gaynullina N.I. Epistolyarnoe nasledie Petra Velikogo $v$ istorii russkogo literaturnogo yazyka: avtoref. dis. ... d-ra filol. nauk [Epistolary Heritage of Peter the Great in the History of Russian Literary Language. Dr. philol. sci. abs. diss.]. Almaty, 1996. 54 p.

Galperin I.R. Tekst kak obyekt lingvisticheskogo issledovanija [Text as an Object of Linguistic Research]. Moscow, Komkniga Publ., 2006. $144 \mathrm{p}$.
Ivantsova E.V. Lingvopersonologiya: Osnovy teorii yazykovoy lichnosti [Linguistic Personology: Fundamentals of Linguistic Personality Theory]. Tomsk, Izd-vo Tom. un-ta, 2010. 160 p.

Karaulov Yu.N. Russkiy yazyk i yazykovaya lichnost [Russian Language and Linguistic Personality]. Moscow, Izd-vo LKI, 2010. 264 p.

Tupikova N.A. O vyrazhenii slavyanskoy yazykovoy lichnosti v delovykh tekstakh nachala XVII veka [About Expression of the Slavic Linguistic Personality in Business Texts of the Beginning of the 17th Century]. Vestnik Volgogradskogo gosudarstvennogo universiteta. Seriya 2, Yazykoznaniye [Science Journal of Volgograd State University. Linguistics], 2007, no. 6, pp. 168-173.

Tkhorik V.I. Yazykovaya lichnost: Lingvokulturologicheskiy aspekt»: avtoref. dis. ... dra filol. nauk [Linguistic Personality: Linguocultural Aspect. Dr. philol. sci. abs. diss.]. Krasnodar, 2000.304 p.

Konstantinov F.V., ed. Filosofskaya entsiklopediya [Philosophical Encyclopedia]. Moscow, Sovetskaya entsiklopediya Publ., 1970, Vol. 5. 740 p.

Shpet G.G. Mysl i Slovo. Izbrannye trudy [Thought and Word. Selected Works]. Moscow, Rossiyskaya politicheskaya entsiklopediya Publ., 2004. $688 \mathrm{p}$.

Shtayn K.E. Garmoniya poeticheskogo teksta [The Harmony of the Poetic Text]. Stavropol, Izd-vo SGU, 2006. 646p.

Engelgardt B.M. Fenomenologiya $i$ teoriya slovesnosti [Phenomenology and the Theory of Literature]. Moscow, Novoe literaturnoe obozrenie Publ., 2005. 464 p.

Golev N.D., Shpilnaya N.N., eds. Yazykovaya lichnost: Modelirovanie, tipologiya, portretirovanie. Sibirskaya lingvopersonologiya [Linguistic Personality: Modeling, Typology, Portraiture. Siberian Linguistic Personology]. Moscow, Lenand Publ., 2014, iss. $1.637 \mathrm{p}$.

Golev N.D., Melnik N.V., Olenev S.V., eds. Yazykovaya lichnost: Modelirovanie, tipologiya, portretirovanie. Sibirskaya lingvopersonologiya [Linguistic Personality: Modeling, Typology, Portraiture. Siberian Linguistic Personology]. Moscow, Lenand Publ., 2016. iss. 2. 432 p.

Yatskevich L.G. Struktura poeticheskogo teksta [The Structure of the Poetic Text]. Vologda, Rus Publ., 1999. $240 \mathrm{p}$. 
A.B. Загуменнов. Герменевтико-феноменологический аспект изучения языковой личности

\section{Information About the Author}

Aleksandr V. Zagumennov, Postgraduate Student, Department of Russian Language, Journalism and Communication Theory, Vologda State University, Lenina St., 15, 160000 Vologda, Russian Federation, zaw1991@mail.ru, http://orcid.org/0000-0002-2440-3918.

\section{Информация об авторе}

Александр Владимирович Загуменнов, аспирант кафедры русского языка, журналистики и теории коммуникации, Вологодский государственный университет, ул. Ленина, 15, 160000 г. Вологда, Российская Федерация, zaw1991@mail.ru, http://orcid.org/0000-0002-2440-3918. 